\title{
Ocean reanalyses
}

Book or Report Section

Published Version

Haines, K. (2018) Ocean reanalyses. In: Chassignet, E. P., Pascual, A., Tintoré, J. and Verron, J. (eds.) New Frontiers in Operational Oceanography. GODAE OceanView. ISBN 9781720549970 doi: https://doi.org/10.17125/gov2018 Available at http://centaur.reading.ac.uk/80495/

It is advisable to refer to the publisher's version if you intend to cite from the work. See Guidance on citing.

Identification Number/DOI: https://doi.org/10.17125/gov2018 $<$ https://doi.org/10.17125/gov2018>

Publisher: GODAE OceanView

All outputs in CentAUR are protected by Intellectual Property Rights law, including copyright law. Copyright and IPR is retained by the creators or other copyright holders. Terms and conditions for use of this material are defined in the End User Agreement. 


\section{CentAUR}

Central Archive at the University of Reading

Reading's research outputs online 


\title{
Ocean Reanalyses
}

\author{
Keith Haines \\ Meteorology Dept., University of Reading, Earley Gate, Reading RG6 6AL, UK
}

Ocean reanalyses are becoming increasingly available and useful, and may eventually attract a similar applications base as atmospheric reanalyses. Here we look at how they are being evaluated against both assimilated and independent data, and emphasise that circulation and transport estimates are critical. The Ocean Reanalysis Intercomparison project, ORA-IP, has been comparing many products for consistency on a regional and global basis, including ocean heat content, air-sea fluxes, and recently polar properties including sea ice. The Atlantic meridional overturning circulation as measured by the RAPID array at $26 \mathrm{~N}$, is now a challenging new target for simulation. This chapter shows that reanalyses may represent interior ocean basin circulations well (better than free-running models) but they still fail to consistently constrain boundary currents, where most meridional heat transport takes place. There is new work ongoing to try to physically interpret observation increments in reanalysis products, and to look at how to best develop long period reanalysis in earlier years when ocean observations were scarce. Finally, we look at new coupled ocean-atmosphere reanalysis that, by always maintaining a coupled ocean-atmospheric boundary layer, may lead to reduced assimilation increments and air-sea fluxes across domains.

\section{Introduction}

7 his chapter will focus on reanalyses in the oceans and will not look at any of the assimilation methods involved in any detail. Although atmospheric reanalyses have become ever more widely used in the past two decades, with much of the pioneering work done at the European Centre for Medium-Range Weather Forecasts (ECMWF), the corresponding use of ocean data to produce ocean reanalyses is still rather less established. First some terms:

Analysis: It is a complete discretised description of the atmosphere or ocean based on assimilating data against model background data that contains information about past data brought forward to the current time thorough model prediction. Analysis is performed at operational weather forecasting centres every day or more frequently, in order to initialise numerical forecasts. It always uses the most up-to-date version of the data, the numerical weather prediction products, or the operational oceanography, model and data assimilation system. Because the model and data assimilation systems are constantly evolving and new ideas are being incorporated, the analyses on which the forecasts are based would not be suitable to interpret through time.

Reanalysis: The same procedure is used as in making an analysis, but the model and assimilation system are kept constant through time and the reanalysis uses this fixed system to produce the best estimate it can of the whole history through the observational record. It is a very 
expensive procedure because modern models and assimilation systems are expensive to run, having expanded to run on the biggest computers for daily data. But now we want to run multiple decades of data through covering past years. Therefore, reanalyses are generally run with lower spatial resolution than current operational suites, at least for the atmosphere.

State estimation: In the ocean, timescales of water mass changes below the surface are long, therefore data on water mass properties may be useful for long timescales, e.g. decades. Longwindow data assimilation methods have been pioneered by the Estimating Climate and Circulation of the Oceans consortium to fit ocean data over long time periods. Essentially, this is tuning of an ocean model by modifying surface forcing (winds, fluxes) or interior mixing to fit observations, using 4Dvar. The strength of this approach is that unphysical data increments are avoided, however the method is hard to apply if the system is very non-linear, as is the case in high-resolution models, and limited convergence to the observed data can be obtained.

Both reanalyses and state estimates are starting to be compared and used for similar purposes, so it remains to be seen whether one methodology is any better than the other. Reanalyses have the advantage of being available as an, albeit expensive, by-product of forecasting operations and thus there are many ocean reanalyses available to the community.

\section{Assimilated Datasets}

Ocean datasets available to be assimilated into reanalysis products vary hugely through time. Operational oceanography took off in 1992 with the arrival of satellite altimetry giving 10-day views of the global sea surface height. This is the mainstay for providing eddy information in the upper ocean, as well as for monitoring global sea level change. It is also enormously helpful that this dataset has had consistent data coverage since 1992, with the TOPEX and Jason satellite series (and future Sentinel 6), supplemented by one to three additional altimeters for shorter periods, allowing long-term comparisons to be made throughout the reanalyses. Sea surface temperatures (SSTs) have been measured globally using satellite infrared radiation since 1979, but atmospheric correction is challenging in the early years and cloud cover often prevents infrared radiation measurements of the surface. Improving the quality of older satellite SST observations is an active research topic, e.g., through the European Space Agency Climate Change Initiative, (http://www.esa-sst-cci.org/). Ship-based observations go back a century or more (e.g., ICOADS), but the quality and coverage is very variable. Reanalyses before 1990 or so tend to rely on gridded SST products based on statistical modelling from the available observations, e.g. HadISST, Rayner et al. (2003). Sea ice extent also has a good satellite observational record and has become an important target for ocean and climate reanalyses in recent years because of the rapid decline in Arctic sea ice, and operational centres have made increasing efforts to use these data in the last few years. The upper $400 \mathrm{~m}$ of the equatorial $\left( \pm 10^{\circ}\right)$ oceans began to be monitored from the early 1990s with moored arrays, starting with TAO/TRITON in the Pacific, and extended to include PIRATA in the Atlantic and RAMA in the Indian Ocean. These were established to enable El Niño-Southern Oscillation operational 
forecasting and are the basis upon which ocean reanalyses at many national weather forecast centres have been built.

Since around 2004, global subsurface observations have been dominated by Argo profiling floats, measuring temperature and salinity down to $2000 \mathrm{~m}$ or so. This still leaves the deep ocean below $2000 \mathrm{~m}$, the polar seas with ice cover, and critical flow regions such as western boundary currents, under-observed. Prior to this, Argo subsurface observations were very northern hemisphere and summer dominated with many more temperature-only measurements (salinity is harder to measure accurately), and they were confined increasingly nearer to the surface going back in time. The World Ocean Database maintained by NOAA (www.nodc.noaa.gov/OC5/WOD/pr_wod.html), the ENSEMBLES database (e.g., EN4, www.metoffice.gov.uk/hadobs/en4) maintained by the Hadley Centre, or the CORA product maintained by IFREMER (www.coriolis.eu.org/Data-Products/Products/CORA), all provide historical in situ ocean profile data available for ocean reanalyses. Some centres also provide gridded in situ products using statistical data melding methods, e.g., the CMEMS ARMOR product. Older mechanical bathythermograph (MBT) and expendable bathythermograph (XBT) observations require careful calibration before assimilation into long period reanalyses, as is underway in the International Quality Controlled Ocean Database (IQUOD) project, http://www.iquod.org. More recent observational datasets such as sea surface salinity from SMOS and Aqua, and surface water (mass) distributions from GRACE will provide new targets for inclusion in reanalyses, but currently these data are not accurate or long enough to have been used much in reanalyses.

\section{Ocean Reanalyses and Metrics: Examples}

Table 19.1 shows a selection of currently available ocean reanalyses. In Europe the operational community has selected the NEMO (Nucleus for European Modelling of the Ocean) as a community model for development, and several reanalyses use this with fairly similar modelling although different assimilation configurations. U.S. reanalyses have greater diversity, using models such as the Modular Ocean Model (MOM), the MIT General Circulation Model (MITGCM), or the hybrid isopycnal model HYCOM (Hybrid Coordinate Ocean Model). Global ocean reanalysis products are also available from Japan and Australia. Many of these products from operational centres focus on the period after 1992 when operational oceanography started to take off, but there is increasing interest in longer term products, e.g. from 1950s onwards, when current atmospheric reanalyses are now available for ocean forcing. There is a strong interest in ocean initial conditions for decadal prediction purposes from these earlier periods. With the recent arrival of century-long atmospheric reanalyses (e.g. CFSR, ERA-20C, the 20th Century Reanalysis Project), such ocean or coupled reanalyses are now also being attempted (see later in the chapter).

Two kinds of metric might generally be considered to benchmark ocean reanalyses: the fits to the assimilated data and the fits to independent, non-assimilated data. Fig. 19.1 shows data 
from the Copernicus quality control document (see legend) on the fit of global subsurface temperature and salinity data to observations in the GLORYS reanalysis product. The rapid improvement as Argo data arrives is clear for both temperature and salinity, although seasonal temperature root mean square (RMS) errors up to $1.5^{\circ} \mathrm{C}$ can still be seen in the top $150 \mathrm{~m}$. A surface to subsurface mean salinity bias dipole can be seen in the same depth range, perhaps reflecting problems with vertical mixing in the upper ocean? More challenging is to assess the circulation in these reanalysis systems. Currents and transports are generally not directly observed or assimilated and yet such information is critical for both climate and forecasting applications of reanalysis data. Near-surface currents are monitored independently by drifters, and deeper currents at $1000 \mathrm{~m}$ by the drifts in Argo float positions. Major current systems are reproduced but near-surface currents are more confined than in the drifter data, and the deep currents are more dispersed than the Argo drifts reveal. The combination of hydrography data (from Argo floats or CTDs) and altimetry are both needed to reproduce upper ocean current structures (Fig. 19.2). Transports of mass heat and freshwater have been estimated at World Ocean Circulation Experiment sections for example, and are being monitored continuously at a few sections such as by the RAPID array at $26^{\circ} \mathrm{N}$ in the Atlantic. We will look at this transport section in more detail later.

\begin{tabular}{|c|c|c|c|c|}
\hline & Name & Model Resolution & DA Scheme & $\begin{array}{l}\text { Atmospheric forc- } \\
\text { ing }\end{array}$ \\
\hline 1 & CGLORS025v5 & $\begin{array}{l}\text { NEMO3.2-LIM2; 1/4 X 1/4 50z-lev- } \\
\text { els }\end{array}$ & $\begin{array}{l}\text { 3DVar (Sea-ice } \\
\text { conc+relaxed ice- } \\
\text { thickness) }\end{array}$ & ERA-Interim \\
\hline 2 & ECDA3 & MOM4-SIS, 1 x 1 50z-levels & EnKF coupled DA & $\begin{array}{l}\text { Coupled O-A } \\
\text { model }\end{array}$ \\
\hline 3 & GECCO2 & MITgcm, 1x1 (1/3) 50z-levels & 4DVar & NCEP \\
\hline 4 & GLORYS2v4 & NEMO3.1-LIM2 1/4 X 1/4 75z-levels & $\begin{array}{l}\text { Reduced-Kalman } \\
\text { SEEK filter }\end{array}$ & ERA-Interim \\
\hline 5 & Glosea5-GO5 & NEMO3.4-CICE, 1/4 x 1/4 75z-levels & $\begin{array}{l}\text { NEMOVAR 3D } \\
\text { FGAT }\end{array}$ & ERA-Interim \\
\hline 6 & MOVE-G2i & $\begin{array}{l}\text { MRI.COM3-CICE4, 1/2 x } 1 \text { 52z- } \\
\text { levels }\end{array}$ & Multivariate 3DVar & JRA55 \\
\hline 7 & ORAP5 & $\begin{array}{l}\text { NEMO3.4-LIM2, 1/4 x 1/4 75z-lev- } \\
\text { els }\end{array}$ & $\begin{array}{l}\text { NEMOVAR 3D } \\
\text { FGAT }\end{array}$ & ERA-Interim \\
\hline 8 & SODA3.3.1 & $\begin{array}{l}\text { GFDL-MOM5-SIS, 1/4 X 1/4 50z- } \\
\text { levels }\end{array}$ & OI & NASA MERRA2 \\
\hline 9 & TOPAZ4 & $\begin{array}{l}\text { HYCOM-EVP-SI, 12-16km } \\
\text { 28hybrid levels }\end{array}$ & EnKF & ERA-Interim \\
\hline 10 & UR025.4 & $\begin{array}{l}\text { NEMO3.2=LIM2, 1/4 X 1/4 75z-lev- } \\
\text { els }\end{array}$ & OI & ERA-Interim \\
\hline
\end{tabular}

Table 19.1. A selection of ocean reanalysis products using different ocean models and configurations, all global except for TOPAZ4 (Arctic), different assimilation schemes and atmospheric forcings. This particular set of products has been used for the ORA-IP Polar oceans intercomparison, and more details of the reanalyses can be seen in Table 1 of Uotila et al. (2018). 
global : Temperature Mean Misfit (region 0)

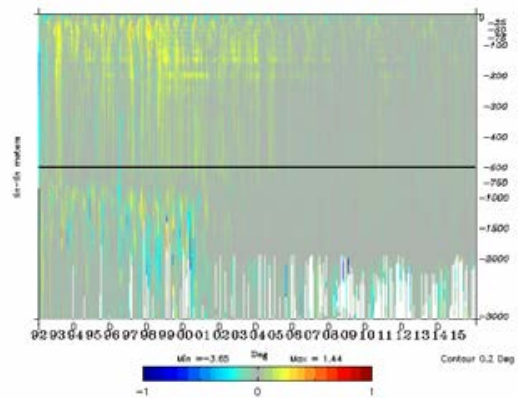

global : Salinity Mean Misfit (region 0)

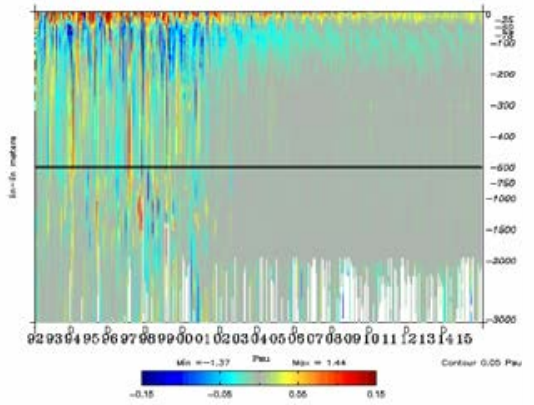

global : Temperature Rms Misfit (region 0)

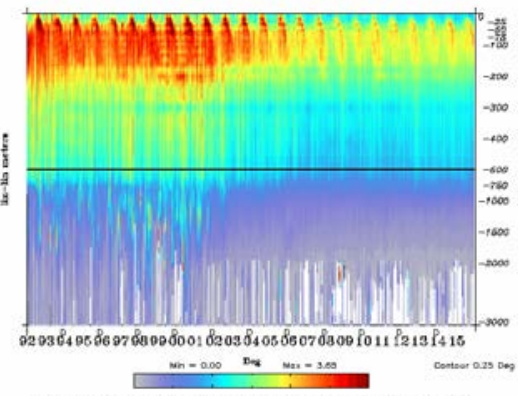

global : Salinity Rms Misfit (region 0)

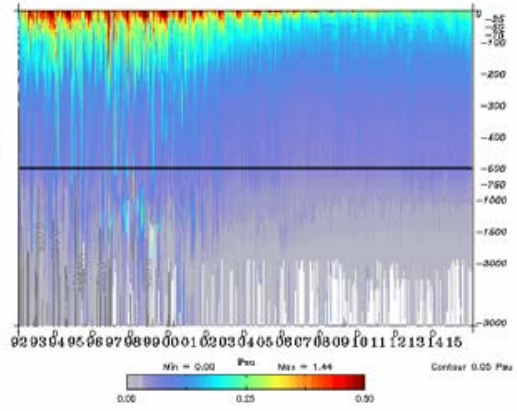

Figure 19.1. Temperature (top) and salinity (bottom) misfits (Obs-model) to global ocean data through time from the Copernicus services global model (GLORYS), reproduced from the online quality assurance document (http://marine.copernicus.eu/documents/QUID/CMEMS-GLO-QUID-001-025.pdf). Left figures show the global mean biases as function of depth and right figures show the RMS errors. Red color, +ve, in the bias shows a cold or fresh bias. The reduction in errors is very clear after the introduction of Argo data, 2005-07.

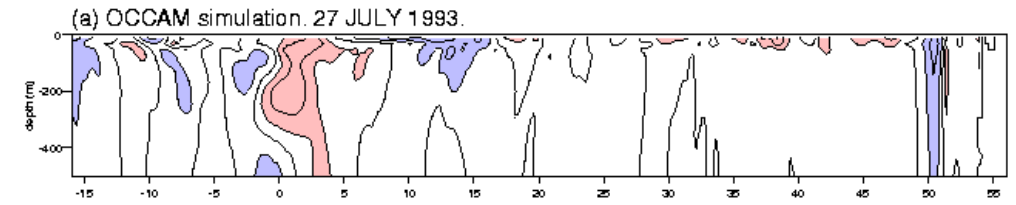

(b) OCCAM WITH XBT ASSIMILATION. 29 JUNE - 26 ALGUST 1993.

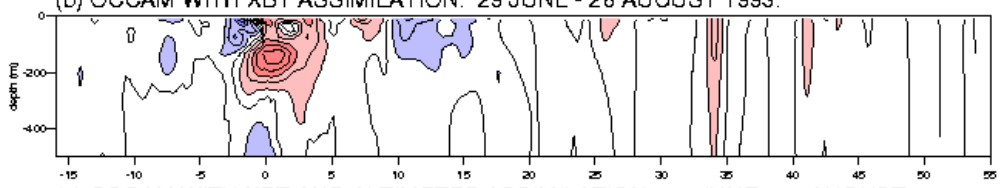

(c) OCCAM WITH XBT AND ALTIMETER ASSIMILATION. 29 JUNE - 26 ALGUST 1993
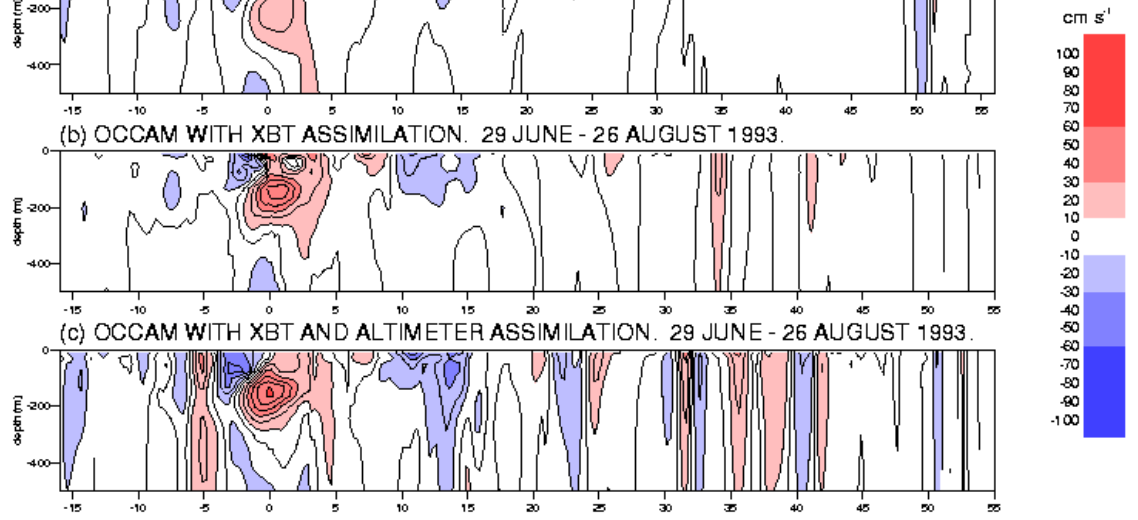

(d) WOCE P14 ADCP DATA. 29 JUNE - 26 AUGUST 1993.

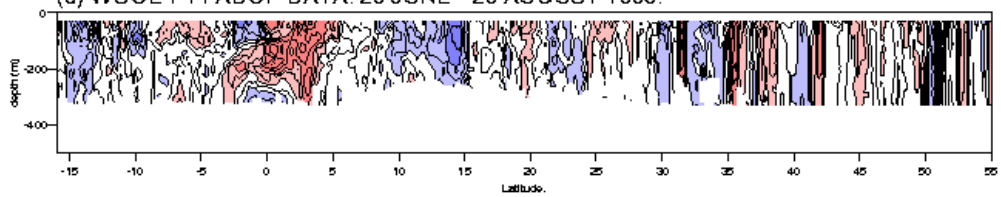

Figure 19.2. Zonal currents in simulation and assimilation experiments with a $1 / 4$ global ocean model (OCCAM, Webb et al., 1998) shown as a N-S section through the Pacific in 1993 following the World Ocean Circulation Experiment P14 section occupation. The bottom plot shows independent current data from the on-board acoustic Doppler current profiler. From Fox et al. (2000). 


\section{Ocean Reanalysis Intercomparison}

The Ocean Reanalysis Intercomparison Project (ORA-IP) was initiated in 2011 with the backing of both the GODAE-Oceanview and CLIVAR-GSOP communities, recognising that high-quality ocean reanalysis products are of value to both forecasting and climate variability communities. A special issue of Climate dynamics, and an introduction to the ORA-IP (Balmaseda et al., 2017) covers aspects of many of the ocean reanalysis products as they were five or so years ago. The project saw the population of an ocean reanalysis data server at the Integrated Climate Data Centre in Hamburg (http://icdc.cen.uni-hamburg.de/1/daten/reanalysis-ocean/oraip.html), where data can be found for further studies. The ORA-IP project recently completed a polar oceans intercomparison paper (Uotila et al., 2018) and a North Atlantic intercomparison is now underway (Laura Jackson, personal communication).

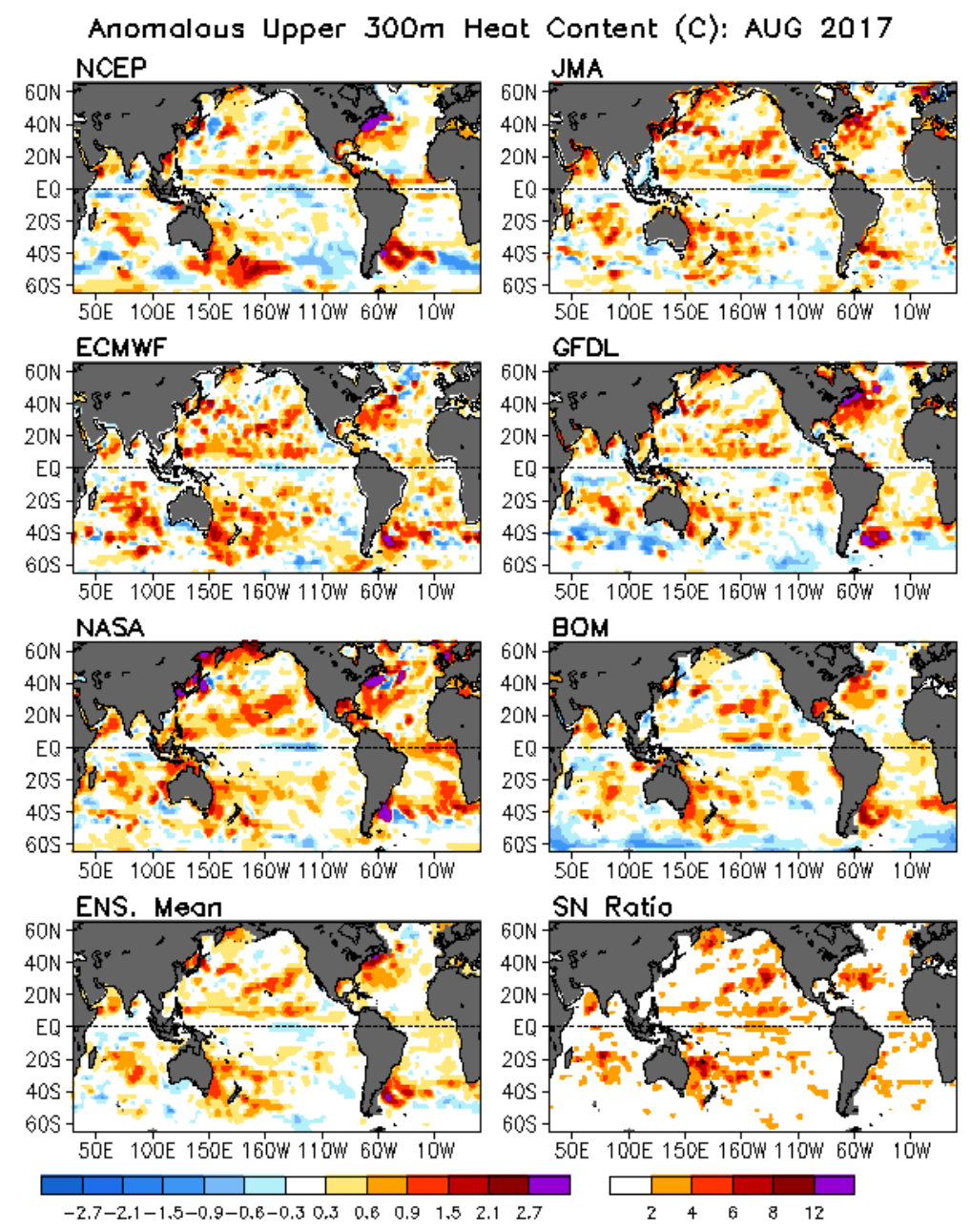

Figure 19.3. Upper ocean (300 m) heat content anomalies for August 2017 from several operational ocean assimilation systems, presented as deviations from each product's 1980-2010 climatology. These plots are available in near real-time from the Real-time Ocean Reanalysis Intercomparison (NOAA Climate Prediction Center). 
To further promote and disseminate data, a website has been set up between the operational seasonal forecasting groups from the NOAA Climate Prediction Center (CPC; http://www.cpc.ncep.noaa.gov/products/GODAS/multiora_body.html) to distribute real-time ocean reanalysis intercomparison data. These data are needed for initialising seasonal forecasts, and making relevant comparisons between the groups will allow better interpretation of forecast differences while presenting a continuously evolving record of the state of the oceans. Fig. 19.3 shows an example of the upper 300 m ocean heat content anomalies from six different products in August 2017, along with an ensemble mean and a signal/noise ratio map, allowing regions of agreement between the products to be easily identified.
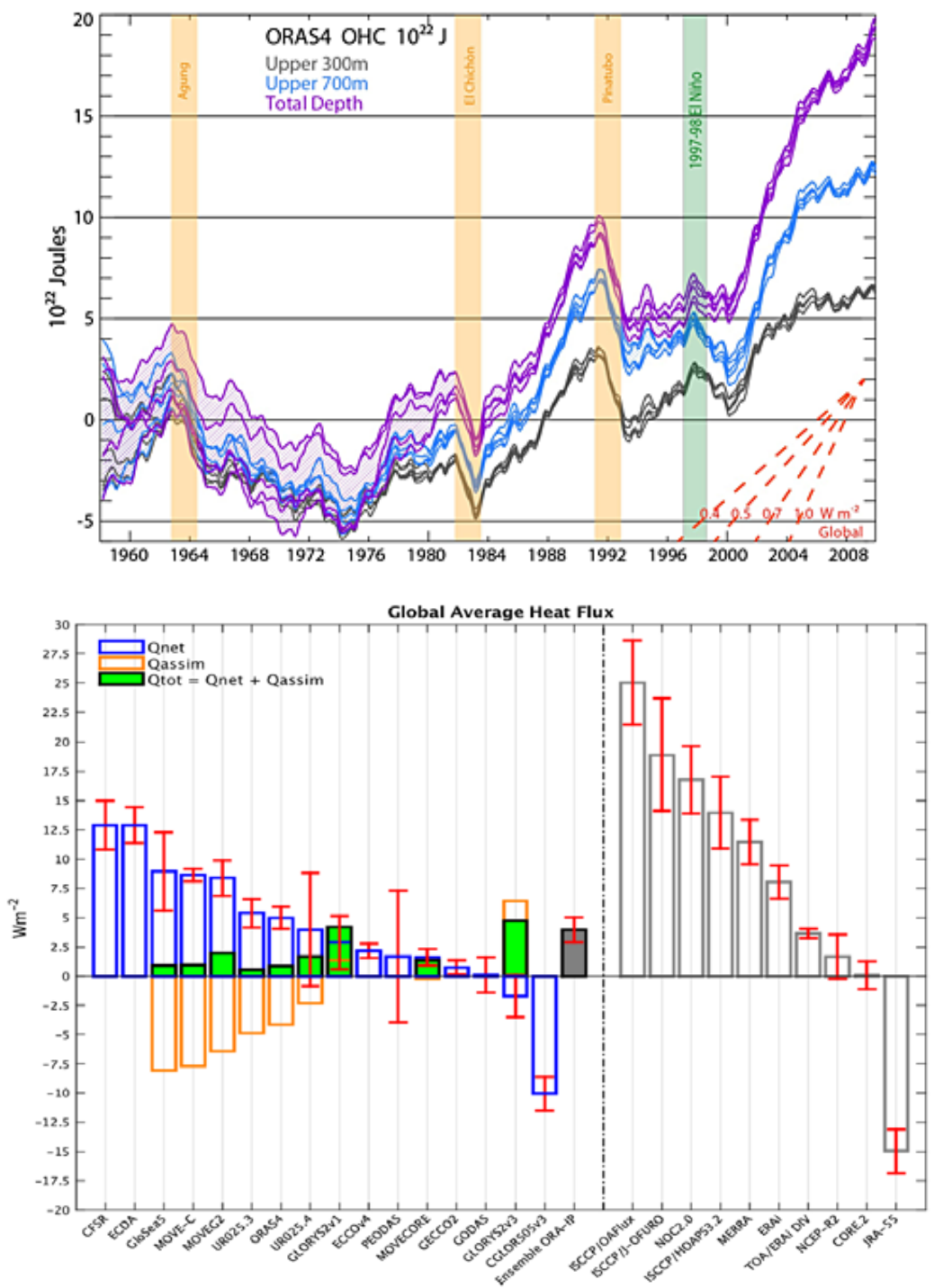

Figure 19.4. Top: Global ocean heat content in the ORAS4 reanalysis for different depth layers through time. The reanalysis is run as an ensemble of five members, which are shown by the different lines. From Balmaseda et al. (2013). Bottom: Global ocean surface heat fluxes from various ocean and atmospheric reanalysis and independent observation based products. From Valdivieso et al. (2017). 
Interannual variability in 0-300m OHC (1993-2009)
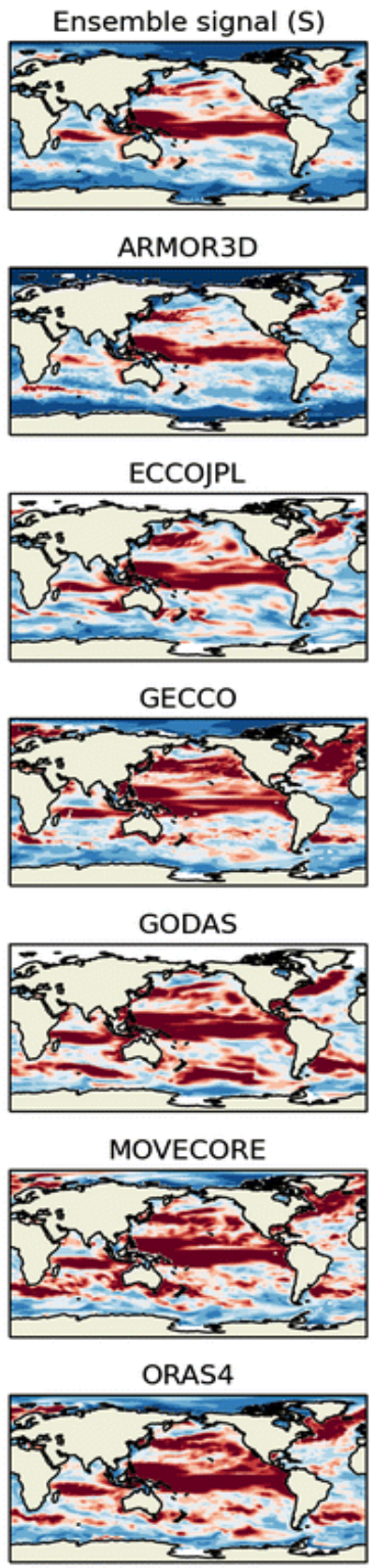

Ensemble noise (N)

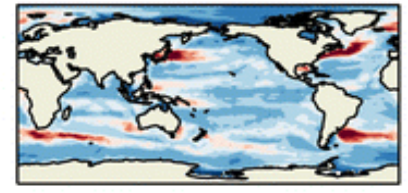

$$
\text { CFSR }
$$
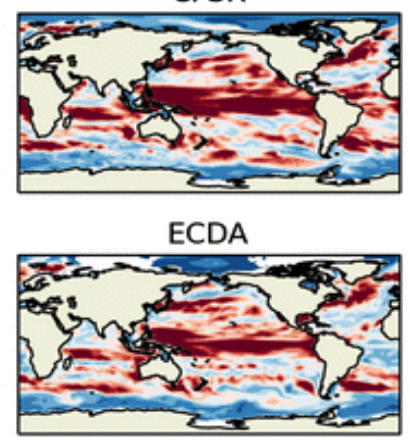

GLORYS2V1
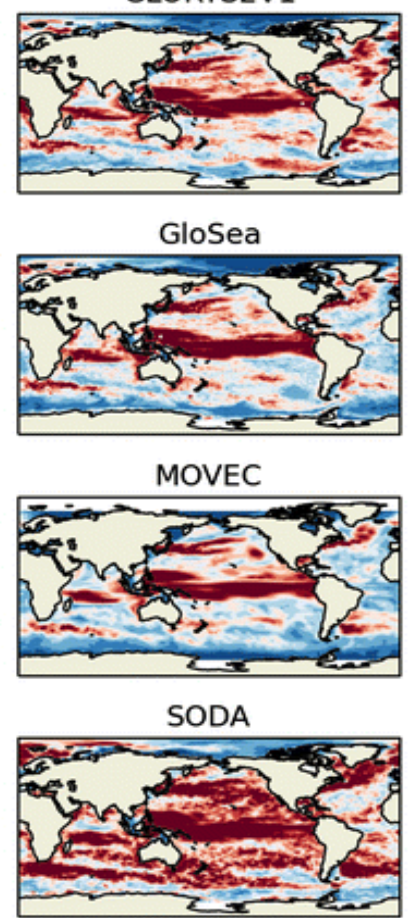

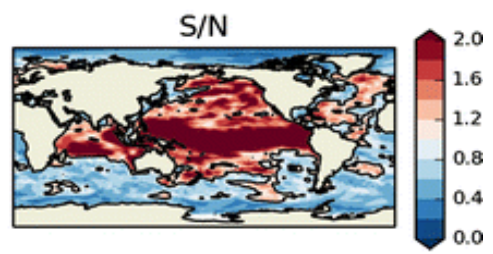

CGLORS

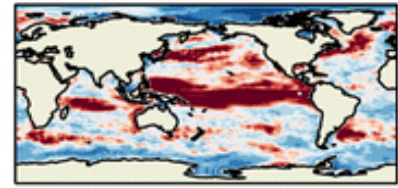

EN3

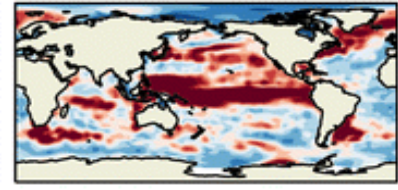

GMAO

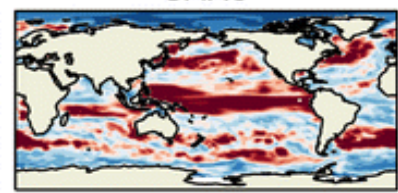

K7
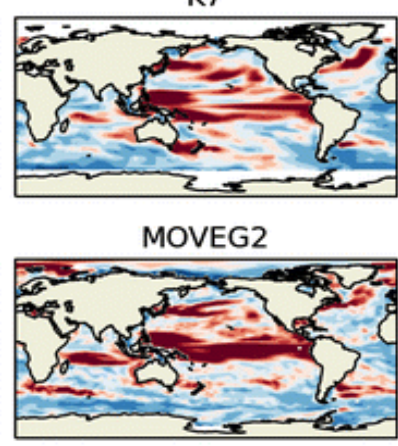

UoR

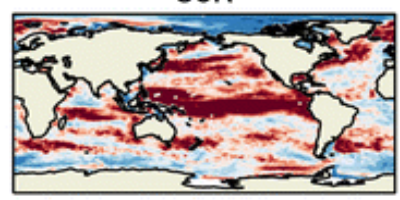

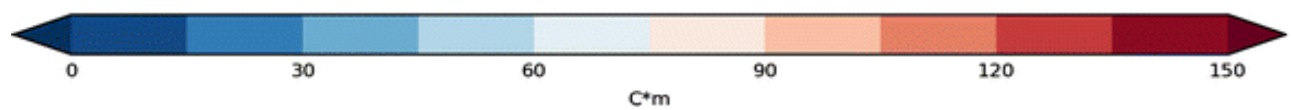



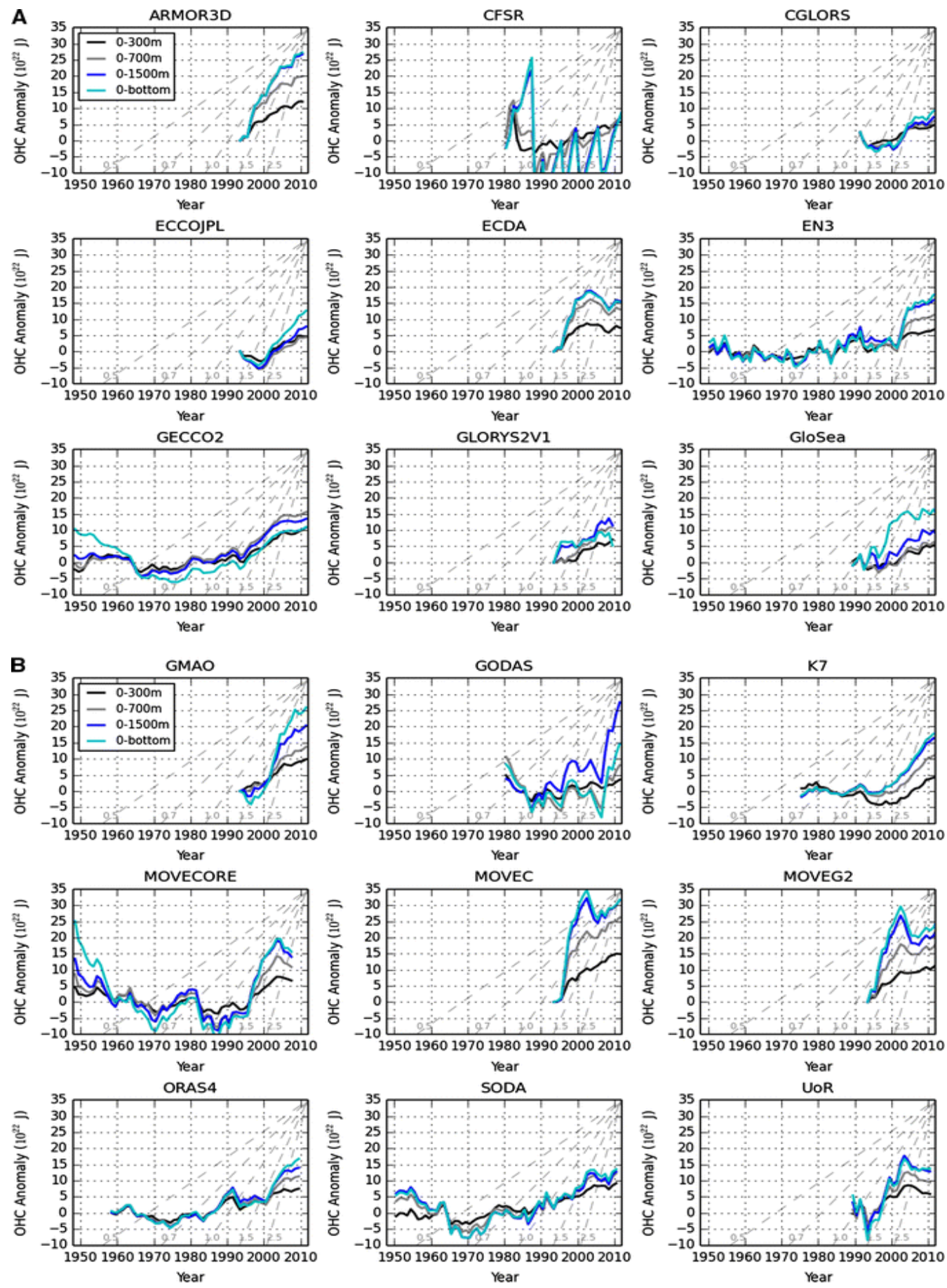

Figure 19.5. Top: Maps of interannual variability in top 300 m ocean heat content for 1993-2010. Bottom: Time evolution of ocean heat content (OHC) in different layers from the different products. Most products only have data back to 1993 but some are longer. From Palmer et al. (2017). 
Ocean heat content - its depth distribution and trends - is particularly important from a climate perspective as it can shed light on global warming of the oceans and the temporal and spatial variability. Balmaseda et al. (2013) used the the European Centre for Medium-Range Weather Forecasts ORAS4 ocean reanalysis to look at the ocean's response to volcanic eruptions and the warming trends at different depth (Fig. 19.4a). While the cooling from volcanic eruptions is all found in the upper ocean, the strong warming since the mid-1990s shows a robust contribution from below $700 \mathrm{~m}$ depth. Palmer et al. (2017) used the ORA-IP project to look at ocean heat content in a wider range of reanalysis products (Fig 19.5). Most but not all show a similar signal of warming below $700 \mathrm{~m}$ depth, although the majority of these products were not long enough to study the signals from volcanic eruptions since the last big eruption event, which was Pinatubo in 1991.Valdivieso et al. (2017) looked at surface heat fluxes within the ORA-IP project (Fig. 19.4b). Observations, e.g., Roemmich et al. (2016), suggest the Argo-monitored oceans (above $2000 \mathrm{~m}$ ) are warming at $\sim 1 \mathrm{~W} / \mathrm{m}^{2}$. Although most ocean reanalysis products show slightly larger warming rates, these rates are comparable (if not lower and hence more consistent) than the fluxes from many atmospheric reanalysis products. Most ocean reanalyses show compensation between surface fluxes adding heat at the ocean surface, and assimilation increments removing heat. This may be due to excess mixing of heat downwards in the models, although GLORYS2v3 is an exception in having assimilation warming the surface, as also suggested by the weak mixing signature in Fig. 19.1.

\section{Intercomparison of Atlantic Meridional Overturning Circulation Transports}

Karspeck et al. (2017) was the only ORA-IP paper to look at transports, focussing on the Atlantic meridional overturning circulation at $26^{\circ} \mathrm{N}$ and using only six long reanalysis products stretching back to the 1950s but stopping in 2007 before the RAPID monitoring time series became available. These results were not very encouraging, with more disagreement in interannual and interdecadal variability between products being shown than for model simulations without assimilation. However, Jackson et al. (2016) showed that the current UK Met Office reanalysis system appears to capture well the recent geostrophic variations in the Atlantic meridional overturning circulation at $26^{\circ} \mathrm{N}$. Encouraged by this, further studies have been conducted of the North Atlantic interannual heat budgets in the subtropical and subpolar gyres, see Fig. 19.6.

Different contributors to ocean heat content change in the Met Office Glosea5 reanalysis are followed from $1997-2013$ in the Atlantic subtropical $\left(25^{\circ}-45^{\circ} \mathrm{N}\right)$ and subpolar $\left(45^{\circ}-65^{\circ} \mathrm{N}\right)$ gyres. In many cases the ocean assimilation increments make a large contribution to the changes.

However, the subtropical cooling in 2009-2011 is strongly driven by both surface cooling and reduced heat transport across $25^{\circ} \mathrm{N}$ (see also Cunningham et al., 2013); and the slower subpolar cooling after 2005 (see Robson et al., 2016) is contributed to by reduced heat transport across $45^{\circ} \mathrm{N}$ into the subpolar gyre. Clearly further work is needed, however these kinds of studies are proving very useful in highlighting problems with the current generation of reanalyses. So how reliable are these poleward heat transports in current reanalysis products in general? 

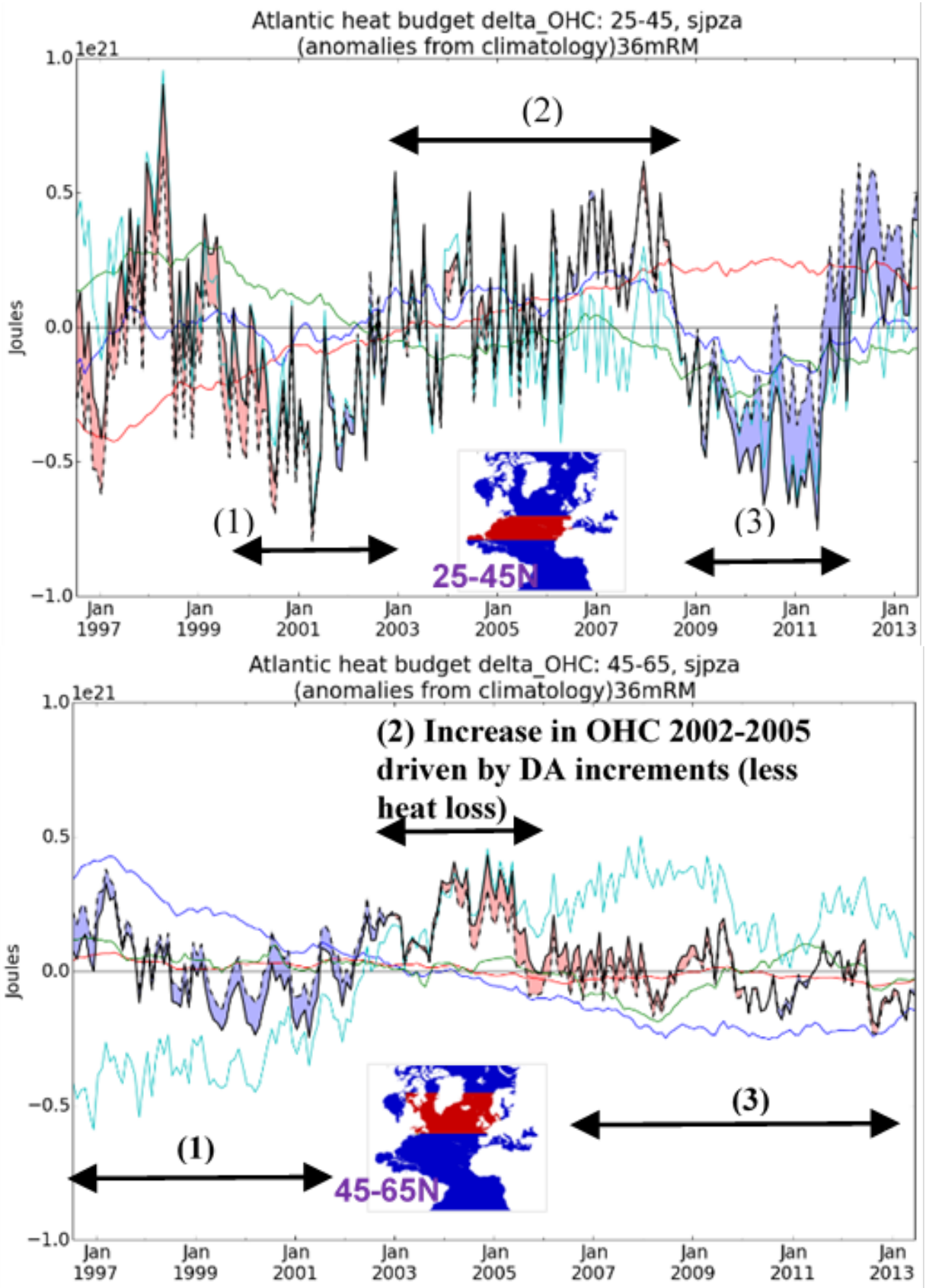

Figure 19.6. North Atlantic regional heat budgets from the Met Office Glosea5 reanalysis. Monthly integrated heat fluxes and the month-to-month changes in ocean heat content (OHC) are shown, so that positive/negative values correspond to positive/negative trends in OHC (Lines are black dashed = monthly change in OHC; green = surface fluxes; blue = ocean heat transport across southern boundary; red = ocean heat transport across northern boundary; cyan = heat input by data assimilation increments; black solid = sum of heat budget components) (Lesley Allison personal communication). Red shading indicates where heat budget contributions (black solid) appear greater than the OHC changes (black dashed), and blue areas show the reverse. Generally, residuals are small. The numbers are periods with gyre warming (2) or cooling $(1,3)$. 


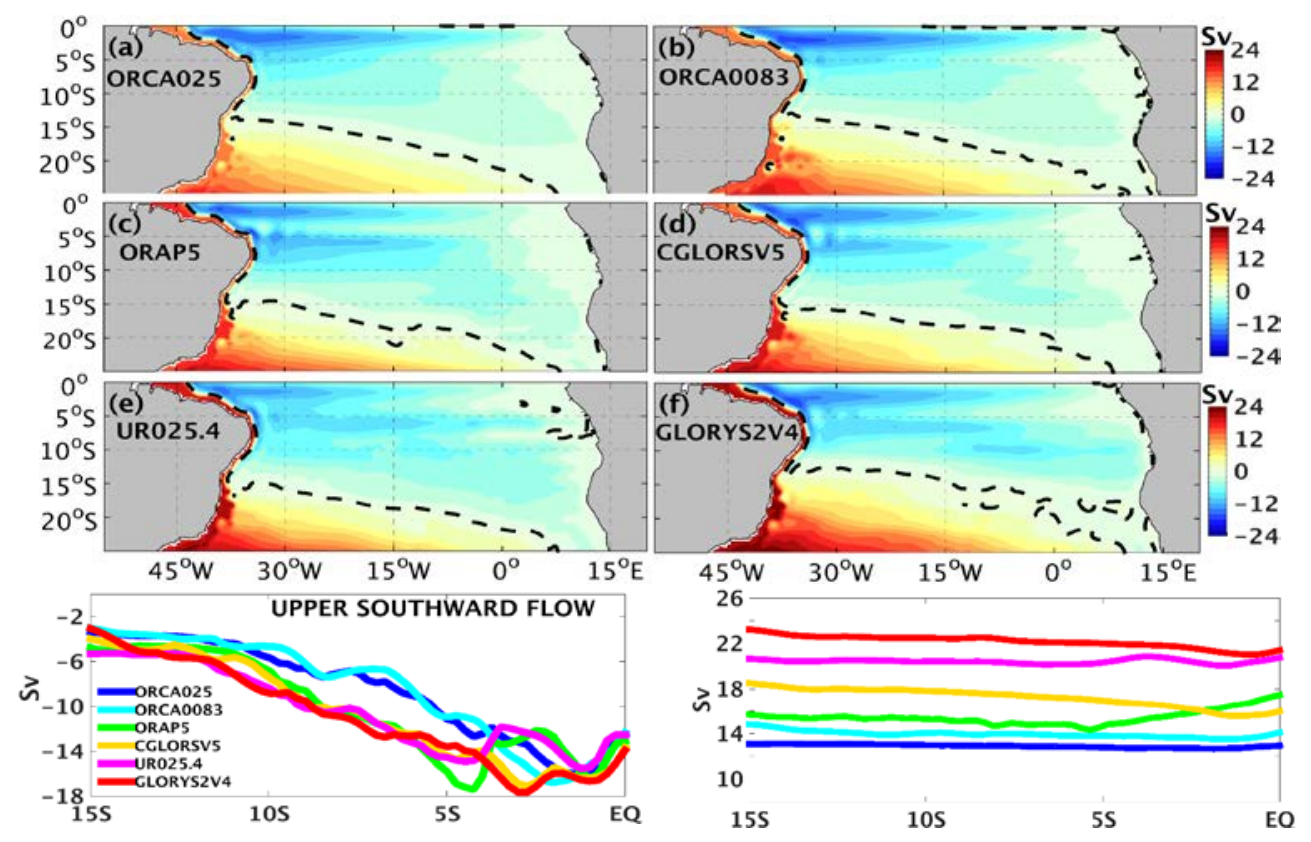

Figure 19.7. (a)-(f) Northward volume transport in the top $1000 \mathrm{~m}$ in the South Atlantic, integrated westwards from the eastern boundary and averages from 1997-2010, dashed lines zero contour. The top two products ORCA025 and ORCA0083 are model simulations at $14^{\circ}$ and $1 / 12^{\circ}$, respectively. The other four products are ocean reanalyses all at $14^{\circ}$. (g) Shows the peak southward flow (-ve) before the E-W integrated flow turns northward near the western boundary. This represents the gyre component of the top $1000 \mathrm{~m}$ ocean circulation. (h) Shows the total northward flow continuing the integration to the western boundary, and is thus a measure of the overturning component of the circulation. From Mignac et al. (2017).

Mignac et al. (2017) showed results for South Atlantic transports in four reanalyses from Table 19.1, along with two free-running models in the more recent 1997-2010 period. They demonstrated that the mean ocean interior circulation in the reanalyses are in fact quite consistent with each other and in better agreement with independent estimates of known ocean currents (for example, Fig. 19.7 shows south tropical current systems reproduced better than in the freerunning models). However, they also showed the reanalysis products disagree near the western boundary in both the upper and deep circulations, as illustrated by the schematic in Fig. 19.8. This message is more encouraging than that of Karspeck et al. (2017) as it suggests the current ocean observing system may allow reproduction of many aspects of circulation, but that more work is required to understand how to better represent and constrain the critical western ocean boundary currents where a lot of the climatically important heat and freshwater transport occurs.

Despite these problems with ocean reanalysis transports, they sometimes still provide useful climatic transport information. When we look at ocean reanalysis heat transport convergences over different ocean basins and compare these with atmospheric reanalysis heat transport convergences for the same regions we often find more agreement between the ocean reanalysis products. This is particularly true for smaller ocean basins and regions where inflow-outflow is particularly restricted in the oceans, such as the Mediterranean and the Arctic.

Analysis of atmospheric heat transports show that by far the most energy transport in the atmosphere is in the form of latent heat in water vapour. It is, therefore, important to follow 
freshwater transports in the oceans that compensate these within the global water cycle. For the first time, Argo data should start to make this possible. Valdivieso et al. (2014) sought to compare the freshwater transports in one ocean reanalysis with what has been published from a hydrographic section data analysis (their Table 4, Table 19.2 below). The considerable disagreement between many of the observational estimates clearly shows that better measurement and monitoring methods are needed, but for most sections the reanalysis freshwater transports are in reasonable consistency. In the next $\left(6^{\text {th }}\right)$ Intergovernmental Panel on Climate Change assessment, there will be a stronger focus on the global heat and water cycles because climate models are known to also strongly disagree and there is an important role for using ocean (and atmospheric) reanalysis transports to develop more reliable observation-based estimates.

\begin{tabular}{|c|c|c|c|c|}
\hline Freshwater Convergence & \multicolumn{2}{|c|}{ Hydrographic Section-Based } & \multicolumn{2}{|c|}{ UR025.4 } \\
\hline \multicolumn{5}{|l|}{ Arctic/Atlantic } \\
\hline $35^{\circ} \mathrm{N}$ to Bering & -0.37 & -0.33 & -0.44 & $-0.49 \pm 0.06$ \\
\hline $24^{\circ}-26^{\circ} \mathrm{N}$ to Bering & +0.12 & -0.29 & -0.16 & $-0.13 \pm 0.03$ \\
\hline $16^{\circ}-19^{\circ} \mathrm{S}$ to Bering & -0.10 & -0.18 & -0.07 & $-0.04 \pm 0.03$ \\
\hline North of $20^{\circ} \mathrm{S}$ & -0.03 & +0.07 & +0.10 & $+0.20 \pm 0.06$ \\
\hline North of $32^{\circ} \mathrm{S}$ & +0.31 & +0.38 & +0.49 & $+0.65 \pm 0.07$ \\
\hline \multicolumn{5}{|l|}{ Pacific } \\
\hline $47^{\circ} \mathrm{N}$ to Bering & -0.27 & -0.11 & -0.16 & $-0.18 \pm 0.02$ \\
\hline $35^{\circ} \mathrm{N}$ to Bering & -0.56 & -0.15 & -0.32 & $-0.44 \pm 0.03$ \\
\hline $24^{\circ} \mathrm{N}$ to Bering & -0.21 & -0.19 & -0.20 & $-0.28 \pm 0.04$ \\
\hline
\end{tabular}

${ }^{a}$ The total transports (last column) include eddies and the \pm values represent annual standard deviations over the 14 year period. Positive is implied net evaporation; negative is implied net precipitation/runoff.

Table 19.2. Comparison of freshwater convergences (Sv) from the UR025.4 reanalysis over the period 1997-2010, with direct estimates from ocean hydrographic sections compiled by Wijffels (2001, Table 6.2.2), and Talley’s (2008) hydrographic section-based analysis ${ }^{\mathrm{a}}$ (Valdivieso et al., 2014).

\section{Interpreting assimilation increments?}

A number of groups have investigated using assimilation increments from ocean reanalyses to interpret physical process errors in models. The suggestion of mixing errors from the persistent dipole biases in Fig. 19.1 was noted earlier. Fig. 19.9 shows a demonstration experiment assimilating the same ocean data into the same ocean model but with the incoming shortwave flux coming from two alternative sources, ERAInterim and the Drakkar forcing (DFS4) based on ERA40. The difference in the assimilation ocean heat content increments closely compensates for the shortwave flux differences, although evidence of the location of some of the assimilated data can still be clearly seen. If other sources of differences (errors) could be discounted it would suggest that surface flux errors may be diagnosable from the assimilation increments. However, this attribution relies mainly on having confidence in the veracity of advective components of the ocean heat content, and we have seen that results presented above suggest this is not yet generally possible with ocean reanalysis products. Nevertheless, as models improve it remains a possibility for the future. 

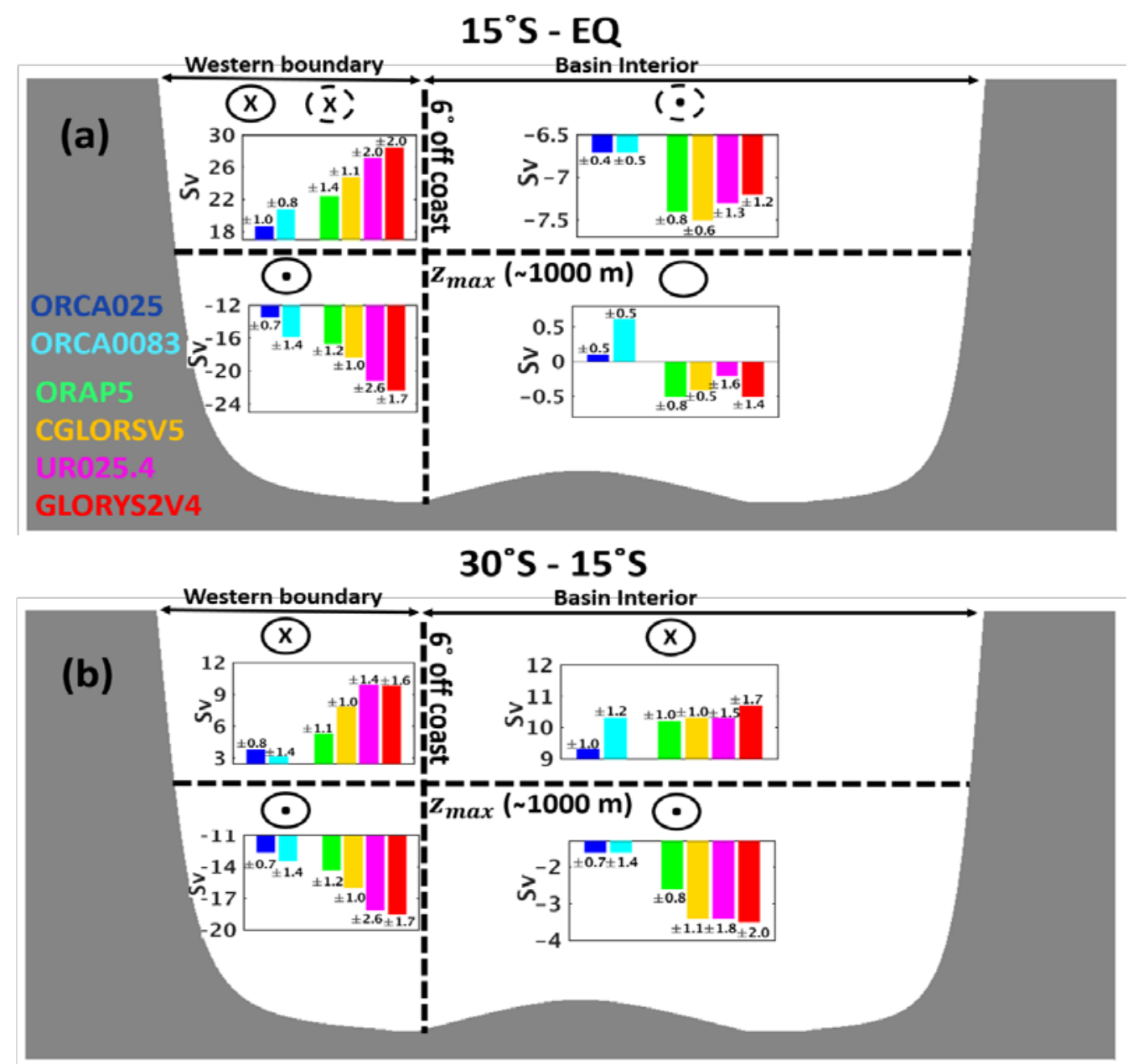

Figure 19.8. Schematic of the South Atlantic 1997-2010 mean circulation averaged over different latitude ranges, and shown for the two model simulation products and the four ocean reanalysis products. The ocean interior and the western boundary flows are separated. From Mignac et al. (2017).

\section{Ocean reanalyses for initialising decadal predictions and the need for} reanalyses with sparse data from the pre-Argo period

One major driver for ocean reanalysis has been to initialise decadal (or at least interannual) climate predictions, which will contribute a great deal to CMIP6. On these timescales, long periods of reanalysis are needed in order to develop sufficient hindcasts of past periods so as to gain statistical confidence. The UK Met Office has been using the DePreSys system to initialise such hindcasts since the pioneering work of Smith et al. (2007). Initialising the upper ocean temperatures in the 1950s or 1960s is very challenging given the sparsity of any subsurface data. That this can be done relies on two factors: (1) the ability to model the upper ocean based on forcing with atmospheric reanalysis data from the period, which is generally much more extensive; and (2) the use of modelling-derived large-scale error covariance patterns based on ocean property variability from within the more extensively observed recent periods. 

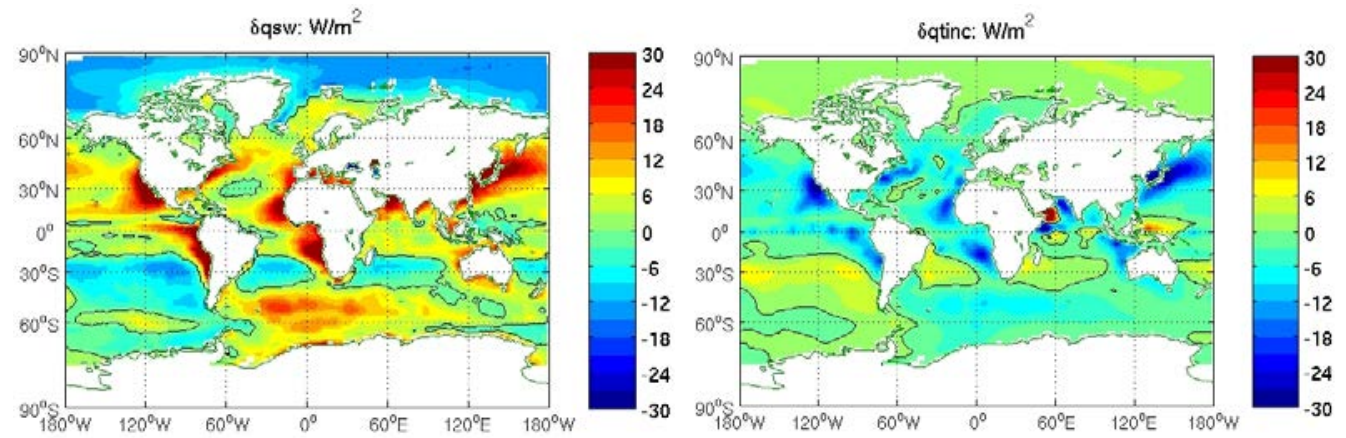

Figure 19.9. Left: Difference in downward shortwave radiation over the oceans at the surface between ERA-Interim and the Drakkar forcing set 4 (DFS4, Brodeau et al., 2010). Right: Difference in ocean heat content increments (expressed as surface flux) from two data assimilation experiments differing only in the shortwave radiation forcing, shown left. The model is NEMO ORCA1 with data assimilation described in Smith et al. (2009) (Valdivieso, personal communication).
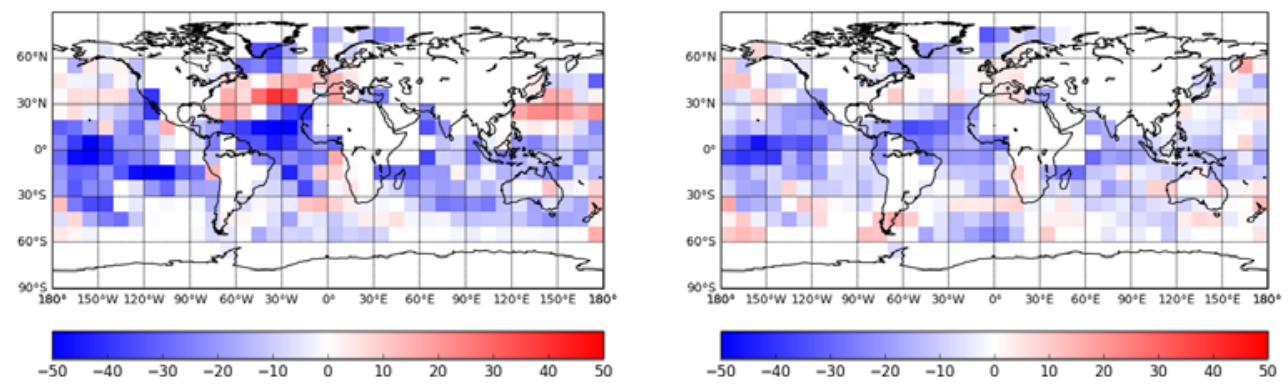

Figure 19.10. Percentage change in RMS SST error when compared to unassimilated observation data (those data removed by subsampling) when assimilating 2010 SST and subsurface profile data subsampled to 1953 densities, into climatological data. Left: standard assimilation method. Right: EOF assimilation method. (Dan Lea, personal communication).

The DePreSys system develops initial ocean conditions from sparse observations using model-based covariances developed through iterating the reanalysis for the last 50-year period, and recycling the large-scale state covariances for the whole period for the next 50-year iteration. This has the effect of developing large-scale covariance patterns from the recent well-observed period and using them at earlier times. This can also be done more directly and explicitly as in the ongoing work at the Met Office (Dan Lea, personal communication). Seasonal Empirical Orthogonal Functions (EOFs) are developed for SST and subsurface temperature and salinity using 20 years of reanalysis data (1989-2010). The current observations are then subsampled to 1953 densities and a climatology used as background data onto which the subsampled data are assimilated using the EOFs, the current operational covariance suite, or a hybrid of the two approaches. The hybrid has been found to perform best with the large-scale EOFs, allowing better reconstruction based on sparse data away from the observation locations, see Fig. 19.10.

\section{Coupled and $20^{\text {th }}$ Century Reanalysis}

All seasonal and decadal reanalyses have always used coupled models, and medium- to longrange weather forecasting from 10 days to monthly timescales are also starting to use coupled 
models. A new generation of coupled atmosphere-ocean reanalyses are currently under development at operational centres. Long period " $20^{\text {th }}$ Century" reanalyses make heavy use of surface observations so it is important that the near surface boundary layers are well reproduced. Fig. 19.11 is based on the new the European Centre for Medium-Range Weather Forecasts $20^{\text {th }}$ Century Coupled Reanalysis (CERA-20C) using coupled data assimilation, which essentially shows how the near surface heat budget is balanced in a long ocean-only reanalysis and a coupled reanalysis, which uses the same ocean assimilation data. As the data volume increases in the ocean-only system a strong cancellation between surface heat flux cooling the ocean surface, and assimilation increments warming the ocean develops. This is avoided in the coupled system because the ocean and atmospheric marine boundary layers are in better balance. The CERA20C reanalysis, despite using variational approach (with a 4DVar atmosphere and 3DVar ocean), is also an ensemble product with 10 members, which gives some measure of variable uncertainty in the product through the century. This varies with data volume and quality, as discussed in Feng et al. (2017).
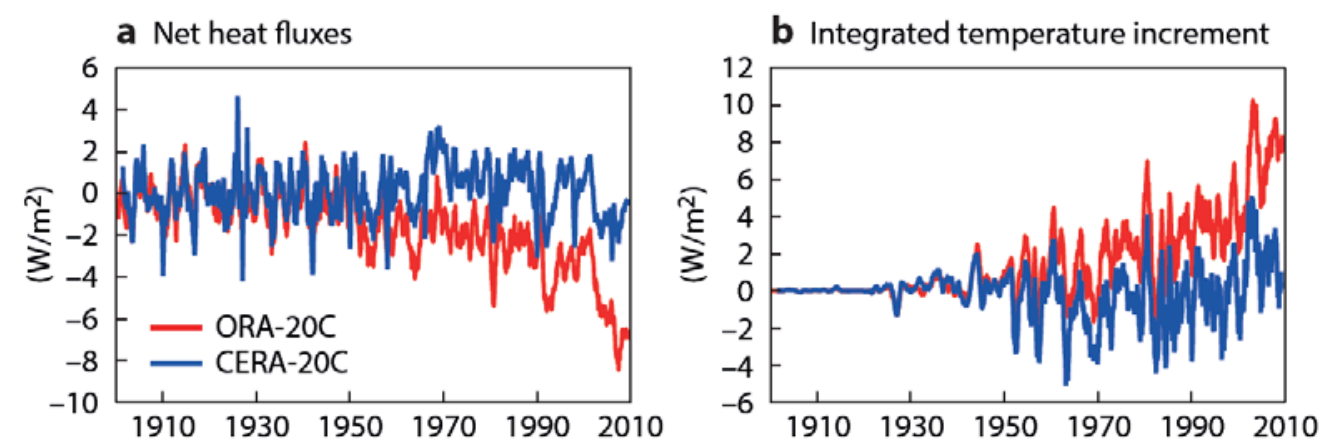

Figure 19.11. Net global surface heat fluxes and integrated temperature increments from 2 the European Centre for Medium-Range Weather Forecasts $20^{\text {th }}$ Century Reanalyses. ORA-20C is an ocean only reanalysis, while CERA-20C is a coupled atmosphere-ocean reanalysis. From Laloyaux et al. (2017).

\section{Discussion and Conclusions}

This chapter has presented a range of ocean reanalysis results looking at multiple products and how well they agree, for example from the ORA-IP, and on applications of the longer data records that they provide. We specifically looked at circulation and transports, as these cannot be observed directly and yet they are critical to both climate change and prediction studies. The current generation of ocean reanalyses are improving, especially for currents and transports in the ocean interior, due to good Argo and altimeter data, but the strong boundary currents are still hard to confidently correct through assimilating ocean current data. Studies of the AMOC from observations such as the RAPID program at $26^{\circ} \mathrm{N}$ are providing useful test cases for assessing ocean reanalysis performance.

We have not covered higher resolution reanalyses, e.g., at $1 / 12^{\circ}$ resolution or higher, with which assimilation is currently performed for marine forecasting applications, both for regional ocean modelling, and for at least two global products: the US Navy HYCOM project and the 
CMEMS NEMO-based global product. Details of the operational advantages of these models are discussed in other chapters of this book.

On longer timescales ocean and coupled reanalyses are starting to be performed for the whole $20^{\text {th }}$ century, and these early reanalysis products are also needed to initialise decadal prediction systems, for example. Improved quality control of some of the early ocean observations, as well as better coupling between the atmosphere and the upper ocean in coupled reanalysis systems, and new ways of using the older sparse observational datasets are all important areas of ongoing development that will have a big impact on ocean reanalyses over the coming years.

\section{Acknowledgements}

I would particularly like to thank contributions from Met Office colleagues, Dan Lea and Lesley Allison, for allowing me to use some of their current research material.

\section{References}

Balmaseda, M. A., K. E. Trenberth, and E. Källén (2013), Distinctive climate signals in reanalysis of global ocean heat content. Geophys. Res. Lett., 40, 1754-1759, doi:10.1002/grl.50382.

Balmaseda, M.A. et al. (2017) The Ocean Reanalysis Intercomparison project (ORA-IP). J. Op. Oceanogr., 8, S1, s80-s97, http://dx.doi.org/ 10.1080/1755876X.2015.1022329

Brodeau et al. (2010) An ERA40-based atmospheric forcing for global ocean circulation models. Ocean Modelling, 31, 88-104, ISSN 1463-5003.

Cunningham, S. A., C. D. Roberts, E. Frajka-Williams, W. E. Johns, W. Hobbs, M. D. Palmer, D. Rayner, D. A. Smeed, and G. McCarthy (2013), Atlantic Meridional Overturning Circulation slowdown cooled the subtropical ocean. Geophys. Res. Lett., 40, 6202-6207, doi:10.1002/2013GL058464.

Feng, X., K. Haines, and E. de Boissason (2017) Coupling of surface air and sea surface temperatures in the CERA-20C reanalysis, Quart. J. Roy. Met. Soc., doi:10.1002/qj.3194/full

Fox, A.D., K. Haines, B. De Cuevas and D.J. Webb (2000) Altimeter assimilation in the OCCAM global model, Part II: TOPEX/POSEIDON and ERS1 data, J. Marine Sys., 26, 323-347.

Jackson, L.C., K. Andrew Peterson, C.D. Roberts \& R.A. Wood (2016) Recent slowing of Atlantic overturning circulation as a recovery from earlier strengthening, Nature Geoscience 9, 518-522 (2016) doi:10.1038/ngeo2715

Karspeck et al. (2017) Comparison of the Atlantic meridional overturning circulation between 1960 and 2007 in six ocean reanalysis products. Climate Dynamics, doi:10.1007/s00382-015-2787-7

Laloyaux et al. (2017) CERA-20C: An earth system approach to climate reanalysis, ECMWF Newsletter, 150, 25-30. doi:10.21957/ffs36birj2

Mignac D., D Ferreira, and K. Haines (2017) South Atlantic meridional transports from NEMO-based model simulations and reanalyses. Ocean Science, 14(1), 53-68. ISSN 1812-0784, doi: https://doi.org/10.5194/os-14-53-2018

Palmer M.D et al. Ocean heat content variability and change in an ensemble of ocean reanalyses. Climate. Dynamics, doi:10.1007/s00382-015-2801-0

Rayner, N. A.; Parker, D. E.; Horton, E. B.; Folland, C. K.; Alexander, L. V.; Rowell, D. P.; Kent, E. C.; Kaplan, A. (2003) Global analyses of sea surface temperature, sea ice, and night marine air temperature since the late nineteenth century J. Geophys. Res, 108, No. D14, 4407 doi:10.1029/2002JD002670

Robson et al. (2016) A reversal of climatic trends in the North Atlantic since 2005. Nature Geoscience, 9; 513-51,7 doi:10.1038/ngeo2727

Roemmich et al. (2015) Unabated planetary warming and its ocean structure since 2006. Nature Climate Change, 5; 240-245, doi:10.1038/nclimate2513

Smith et al. (2007) Improved Surface Temperature Prediction for the Coming Decade from a Global Climate Model. Science, 10 Aug 2007, Vol. 317, Issue 5839, pp. 796-799, doi: 10.1126/science.1139540

Uotila et al. (2018) An assessment of ten ocean reanalyses in the Polar regions. Climate Dynamics, doi:10.1007/s00382-018-4242-z, https://rdcu.be/PkKi. 
$18 \cdot$ KEITH HAINES

Valdivieso, M., K. Haines, H. Zuo and D. Lea (2014) Freshwater and heat transports from global ocean syntheses, J. Geophys. Res. Oceans, 119, doi:10.1002/2013JC009357.

Valdivieso, M., K. Haines, et al. (2017)Surface heat fluxes in ocean and coupled reanalyses. Climate Dynamics, doi:10.1007/s00382-015-2843-3.

Webb et al. (1998) The first main run of the OCCAM global ocean model. Southampton Oceanography

Centre Internal Document No. 34. ftp://ftp.soc.soton.ac.uk/pub/occam/papers/occam_tech1.pdf 